\title{
TEACHING-LEARNING MODEL FOR THE SCIENCE OF ELECTRONICS
}

\author{
Juan Hinojosa (D), Félix Lorenzo Martínez-Viviente (D), Vicente Garcerán-Hernández (D), \\ Ramón Ruiz-Merino $\mathbb{D}$ \\ Universidad Politécnica de Cartagena (Spain) \\ juan.binojosa@upct.es,felix.martineミ@upct.es,vicente.garceran@upct.es,ramon.rui@@upct.es
}

Received November 2018

Accepted October 2019

\begin{abstract}
We present a method for the teaching of Electronics, defined as the scientific discipline that studies the movement and behavior of electrons in semiconductor materials and in vacuum. Electronics can be considered as a science with a solid physical foundation. Within the field of Electronics there are different disciplines, some of them can be considered as pure science, while some others are more oriented to applications. Our methodology has been applied to the wide range of courses that develop the different approaches to Electronics, from the physics of semiconductors or the physics of microelectronic devices, generally taught at physics faculties, to microelectronic fabrication technology or microelectronic design, subjects that typically have a more application-oriented character. To ensure an effective learning of these subjects, a teaching-learning model has been established. This model involves the criteria for developing the programs and defining objectives according to the curricular competences, as well as the development of a series of activities in which the methods, techniques, forms of presentation and didactic resources most useful to achieve the proposed objectives will be used. An evaluation system that assesses the effectiveness of the educational process and detects its anomalies is also included. The impact of this method on the effectiveness of the teaching-learning process was evaluated by a comparative analysis of the results of the surveys distributed by the university to the students for the assessment of quality, together with surveys to the lecturers of the subjects of Electronics.
\end{abstract}

Keywords - Science-engineering interaction, Electronics, Learning evaluation, Pedagogical methods.

\section{To cite this article:}

Hinojosa, J., Martínez-Viviente, F.L., Garcerán-Hernández, V., \& Ruiz-Merino, R. (2020).

Teaching-learning model for the science of electronics. Journal of Technology and Science Education, 10(1), 87-100. https://doi.org/10.3926/jotse.604

\section{Introduction}

At the beginning of the 2010s, we have witnessed a transformation of the curricula of the degrees of the Spanish universities to adapt them to the guidelines of the European Higher Education Area (EHEA) in order to favor European convergence in education (Díaz-Álvarez \& Pons-Fanals, 2011; Vidal-Prado, 2012; Cobo-Ortega, 2015). Today, the structure of university studies in Spain is based on three levels of training: degree, master and doctorate. The official degrees that emanate from the different training levels of the Spanish university system are valid throughout the EHEA. 
The purpose of this article is to present the methodology used to teach different subjects of the field of Electronics, where Electronics is considered in its broadest sense as a science with physical principles and engineering applications (Felder \& Silverman, 1988). It is based on the experiences realized in the degrees in Telecommunications Systems and Telematic Engineering at the Higher Technical School of Telecommunications (ETSIT) of the Polytechnic University of Cartagena (UPCT) to teach four subjects of Electronics: Electronic Components and Devices, Electronic Circuits and Functions, Electronics for Telecommunications, and Design and Manufacture of Electronic Circuits. All these subjects have six ECTS (European credit transfer and accumulation system) credits. The first one is a fundamental or basic subject, the second and third ones are compulsory subjects, and the last one is an optional subject. The first two subjects are taught during the second course, while the third and fourth are imparted, respectively, in the third and fourth year.

The realization of a teaching-learning model that appropriately guarantees the teaching in Electronics should consider the following points: methodology and definition of objectives according to curricular competences, development of a series of activities in which these methods will be used, techniques, forms of presentation of the subject and more useful didactic resources to achieve the proposed objectives, and a system of evaluation of the effectiveness of the educational process allowing also to detect its anomalies. The impact of the proposed methodology on the effectiveness of the teaching-learning process will be analyzed through a comparative study of the results of the surveys carried out on students by the university's quality service, as well as through teacher surveys.

\section{Methodology and Objectives}

The elaboration of a didactic for a subject requires addressing methodological aspects of a scientific and pedagogical nature (González \& Triviño, 2018). The organization of each lecture goes through a set of considerations that we will address in this section, such as the methodology and objectives.

\subsection{The Scientific Approach}

Since Electronics has a scientific and technical nature, we believe it is appropriate to consider the didactic method (necessary to carry out an effective work of knowledge transmission) in the context of the scientific method (Lodico, Spaulding \& Voegtle, 2006). It is not possible to give a complete training to the student of a scientific-technological degree without transmitting a scientific methodology that will enable them to fully use their knowledge in the development of their professional activity, since research and development are essential parts of their professional field. In this sense, the teacher must transmit to the student the contents of the program and at the same time stimulate their critical and creative capacity. The scientific method is a process in which experiments are used to answer questions. The application of the scientific method can be divided into three specific cyclic stages as illustrated in Figure 1.

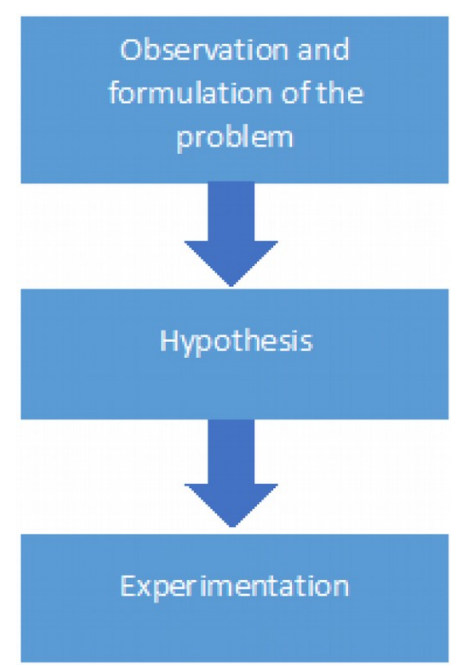

Figure 1. Main stages of the scientific method 


\subsection{Objectives}

To define the objectives that any subject of Electronics should contemplate, we have adapted the Klopfer's taxonomy (Klopfer, 1976). The most important objectives that we intend to achieve according to the curricular competences of Electronics subjects are the following:

- Acquire a basic set of knowledge in Electronics (Analog and Digital).

- Identify and apply the knowledge acquired to habitual and new situations, in order to recognize the problems and solve them with flexibility.

- Identify and properly manipulate instruments, components and laboratory techniques.

- Describe rigorously and with the appropriate language designs and experimental observations. Create an ability to write technical reports.

- Identify, access and use the bibliography search information tools.

- Develop favorable attitudes towards Science in a broad sense (Haladyna \& Shaughnessy, 1982), and Electronics in particular, and assimilate the scientific method as a way of thinking.

- Acquire critical thinking and group work habits.

\section{Teaching Activities}

Any proposal for the program of a subject should consider carrying out a series of activities in which the most useful methods, techniques, forms of presentation of the subject and teaching resources will be used to achieve the previously proposed objectives. The activities through which teaching has been traditionally developed are of several types: theoretical lectures, practices (problems and laboratory), complementary activities, and evaluation. In addition, there are a few hours of tutoring in which the teacher must be available to students, as well as the necessary activities for the development of the end-of-career project. The introduction of methodologies adapted to the European Higher Education Area (EHEA) does not imply the elimination or replacement of these traditional activities, since in most cases there must be theoretical lectures, practices, exams and other complementary activities. What has taken place is an update of the methodologies to improve the effectiveness in achieving the objectives that are intended to be reached with these activities. For this purpose, we propose below some innovative methodologies that we follow in the development of the different didactic activities mentioned above, as they are carried out in the Electronic subjects adapted to the EHEA (Vidal-Prado, 2012).

\subsection{Theoretical Lecture}

The objective of the theoretical lectures is the rigorous and orderly presentation of the theoretical bases necessary for the development of a discipline to a certain group of students. The most used form of presentation of the subject, throughout the course, is usually the lecture, and the method of exposure to explain the content is the use of the blackboard and audiovisual resources (Gotsick \& Gotsick, 1996; Apperson, Laws \& Scepansky, 2008, Rodríguez-García, Hinojosa-Lucena \& Ágreda-Montoro, 2017). Keep in mind that not all students learn in the same way and that not all subjects can be developed in the same way, so it will have to adapt to each particular situation. For this purpose, we present in this article the application of some teaching innovations, some already known and practiced since the implementation of the European Higher Education Area, such as the "flipped classroom", and some other proposed by us and which we have called "dialogued lecture" and "Historicist method".

The flipped classroom aims to break the monotony of the theoretical lectures. It can be realized with some subjects that best suit to this methodology (Walvoord \& Anderson, 2010; Bergman \& Sams, 2012). In this case, the presentation of the subject taught by the teacher is reversed. Students study the contents of the topic at home, for which it is important that students have an available support material, and then we work in classroom to reinforce the knowledge acquired and meet the needs of each student through exercises, problems and projects. 
Not all competences can be acquired through the methodology of the flipped classroom, so it is necessary to look for other methodological innovations for the theoretical lectures. We propose the concepts of "dialogued lecture" and "historicist method". The dialogued lecture is a way of teaching the theoretical lecture in which the acquisition of competences is carried out through an exposition of the contents in a permanent dialogue with the students. It is not simply that the students ask any doubt that may have been raised, nor is it that the teacher asks to the class from time to time if they have understood what he has explained. It is about the students themselves developing the subject topics guided by the teacher. Obviously, this way of giving the lecture is slower than the traditional theoretical lecture, so it will be necessary to select very well the concepts that will be developed in the classroom, limiting itself to the key and essential points of the subject topics, and leaving everything accessory or complementary to the laboratory practices and non-face-to-face work of the student.

On the other hand, the "historicist method" is a way of imparting the lecture that starts from the fundamental concept of the philosophical theory of "historicism", according to which everything human only acquires its true meaning when it is considered as part of a continuous historical process. This concept, together with the intrinsic appeal that history has, allows us to design a fun and entertaining lesson approach for students, in which the development of the lecture revolves around anecdotes about how those concepts arose and the life or biography of the scientists or engineers who made them possible.

\subsection{Practices}

The main objective of the practices is to help the student to fix and assimilate the subjects exposed during the theoretical lectures. Within the practical classes, we distinguish two types: problem classes and laboratory practices. Both lend themselves very well to a methodological innovation known as project-based learning (Dutson, Todd, Magleby, \& Sorensen, 1997; Nunes de Oliveira, 2011). This method is based on different stages in which the student is the main actor in their learning process, as described in Figure 2. During the entire development of the project, the teacher supports the students and acts as a guide. Nowadays, this method is difficult to carry out in the basic and compulsory subjects of the ETSIT of the UPCT, due to the large size of the student groups and the large number of subjects taught in each course. However, its application is possible in the second semester of the last course, dedicated to optional subjects, internships in companies and Erasmus stays. Therefore, this type of methodology has been applied to the optional subject: Design and Manufacture of Electronic Circuits.

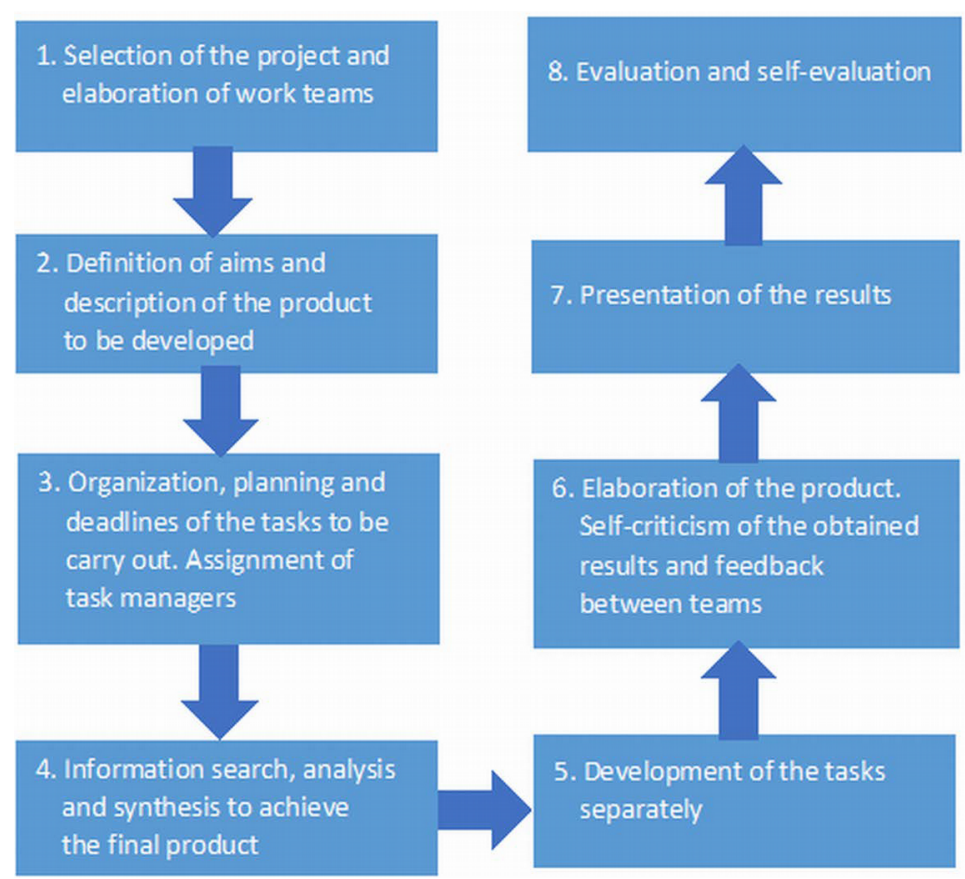

Figure 2. Different stages of the Project-based learning method 


\subsection{Schedule for Queries or Tutoring}

In addition to the previous activities, the teacher has the obligation to establish a schedule for queries or tutoring (Álvarez-Pérez, 2013; Gezuraga-Amundarain \& Malik-Liévano, 2015). The teacher should encourage students to use these hours, since, from a didactic point of view, they allow direct contact with him through individualized attention. In this way, any doubts can be resolved for those students who have difficulties in the contents of the programs, as well as in the development of the different activities. The use of these tutoring, at times not strictly coinciding with the dates before the exams, can be a good indication of the degree of motivation of the students for the subject. In the new framework of the EHEA, the main innovation in this subject has been the introduction of group tutoring. Our experience in organizing these types of tutoring shows that they can be an effective tool for exam preparation. In order to distinguish themselves from a traditional problem-solving class, both the teacher and the students must properly prepare this group tutoring. The best thing for the teacher is to prepare a list of doubts or typical difficulties that his experience with the subject allows him to know that the students will find, and that he may not have had time to deal with the breadth or tranquility necessary within the theoretical lectures. The presentation and resolution of these issues of specific difficulty will raise their own doubts in the students, in addition to those already brought prepared in advance, so that the question time of the group tutoring will be intense and enriching for everybody.

\subsection{End-of-career Works}

The end-of-career project is a key phase in the preparation of university graduates, both in science and engineering, who must be able to use and apply the knowledge and skills acquired throughout the academic courses.

Unlike the rest of the teaching activities, the EHEA has not introduced significant innovations in the end-of-career work, which had already been carried out in practically all the degrees, both humanities and social sciences, natural sciences or engineering since the reforms of the curricula occurred during the 1990s with the application of the LRU (Ley de Reforma Universitaria). From the point of view of the students, practically the only difference they have noticed is that those who wish to obtain the master's degree have to do two final projects, one at the end of the degree and another at the end of the master. The teacher must take into account in his offer of proposals of end-of-career project the different nature of these two works, which must synthesize the skills acquired in their respective degrees.

\subsection{Other Complementary Activities}

Within the complementary activities, those that do not have a predetermined academic arrangement and that, most of the time, have an optional character, are contemplated. Some of them had been realized since before the implementation of the EHEA, but this has brought some novelties. Among them it is worth highlighting two: internationalization and bilingualism. Internationalization is affecting the entire life of the Spanish university, which increasingly seeks to attract students from emerging countries, as well as research talent trained in prestigiously foreign centers. We mention here this reality of internationalization, because one of its dimensions is the possibility of inviting foreign professors to give talks, seminars or workshops to our students, so that a traditional complementary activity thus acquires a new added value. Similarly, Spanish/English bilingualism has been incorporated into university teaching in a generalized way. We mention it specifically in this section because it is in the complementary activities such as lectures or seminars given by invited foreign professors where the second language (English in most cases) begins to appear more naturally.

\subsection{Evaluation}

The evaluation of the students should serve to verify the degree of learning achieved by the students and, in the same way, measure the effectiveness of the teaching activity of the team of teachers (Bloom, Hastings \& Madaus, 1975; Villardón-Gallego, 2006). Thus, the exams offer a very effective form of student-teacher feedback (García-Sanpedro, 2012). Within the framework of the EHEA there have been some innovations in the assessment systems, and teachers/researchers continue to deepen them at this time. An attempt has been made to introduce a continuous assessment system based on deliverables, at 
least as a significant percentage of the overall assessment, and the tendency is that this percentage will increase until, in some cases, the final exam is eliminated. The main difficulty teachers have encountered in implementing this continuous assessment system has been the absence of a teaching support staff similar to the figure of the "teaching assistant" or "TA" of the Anglo-Saxon system. Without this support, in very large groups it is difficult to think about the possibility of correcting some deliverables with sufficient periodicity to allow a continuous assessment. These "TA" are usually students of the last courses or recent graduates who have demonstrated a good acquisition of skills in the subject they are going to support. For them it is like a first part-time job while they finish their studies or probe the labor market, with a small salary that helps them support themselves during this period. In return, the help they can provide is invaluable to make possible not only a true continuous assessment, but also other teaching innovations.

\subsection{Relationship between Teaching Activities and Methodological Innovations}

As a summary of this section we present an illustrative figure (Figure 3) that summarizes the relationship between traditional teaching activities and methodological innovations. Depending on the characteristics of each subject, it may be more convenient to apply one or the other. The important thing is that these new methodologies help to achieve the proposed aims, which are none other than the acquisition of the competences established for each subject. It is not a matter of changing just for the sake of change without knowing the direction, but that innovation must have a clear meaning and purpose, and above all it must demonstrate its effectiveness. Figure 3 relates each methodological innovation to teaching activities in which it is normally more effective, but is not intended to be exhaustive or exclusive. Other possibilities exist and each teacher must evaluate them for their particular case.

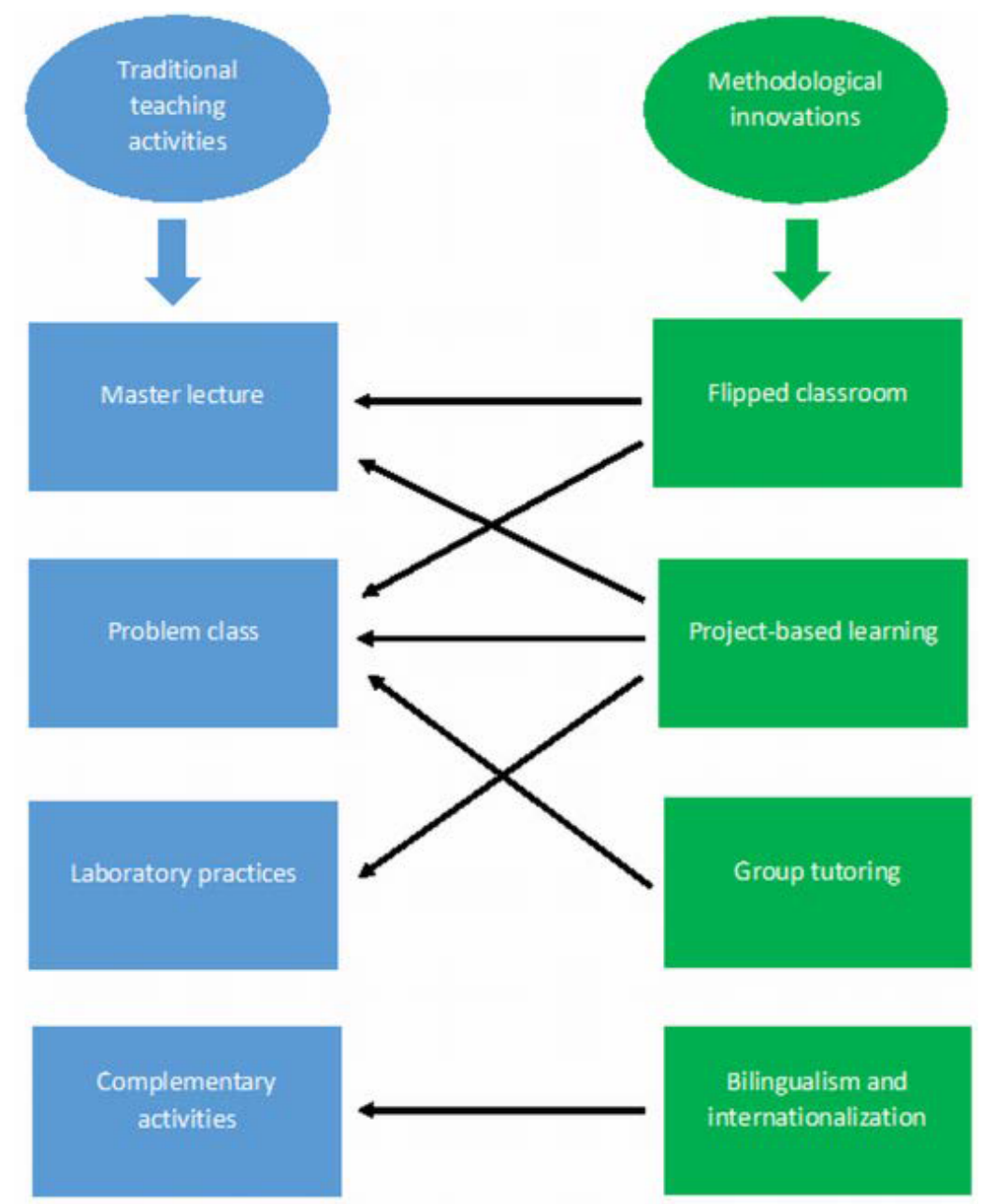

Figure 3. Relationship between teaching activities and methodological innovations 


\section{Practical Application of the Proposed Methodology}

In this section we describe the practical application of the proposed methodology to specific cases of Electronic subjects adapted to the European Higher Education Area at the Polytechnic University of Cartagena. We analyze a case of flipped classroom, another of project-based learning, and finally some new methodologies for the theoretical lecture that we have called the dialogued lecture and historicist method. Finally, teaching innovations applied to complementary activities based on bilingualism and internationalization are also described.

\subsection{Flipped Classroom}

In the subject of third course "Electronics for Telecommunications" of the degree in Telecommunications Systems an activity is carried out that has elements of both flipped classroom and seminar. It is a workshop prepared by the students themselves and entitled "Workshop on Emerging Technologies for Telecommunications". In this activity, students work in groups of 4 or 5 people to prepare a topic related to the contents of the subject, which they should then expose to the class and the teacher (flipped classroom). It is usually a topic of current technological interest, but it must have a good theoretical foundation in the subject. The topics are proposed and assigned by the teacher according to these criteria. For example, during the 2018/2019 academic year the following topics were selected: microsatellites, power amplifiers for radio frequency communications, vacuum tubes in power electronics for radio frequency, radio frequency identification (RFID) technology, and memristors. These topics have not been chosen based on the research lines of the department, so the activity does not have a research orientation. Two of the topics deal about power electronics for telecommunications (amplifiers on the one hand and vacuum tubes on the other hand), so they are directly linked to the subject topics. Two other topics, microsatellites and memristors, are more general, but students are expected to give an approach according to the subject (that is, electronics for microsatellite telecommunication systems, or application of the memristors in specific circuits for telecommunications). It is therefore not a question of generalist expositions, but with a well-defined character. Finally, the RFID topic contains elements of both electromagnetism and electronics, so it can be suitable for various subjects. Therefore, we can see that depending on the topic chosen, the activity may have a flipped classroom character or rather a seminar. In general, we can consider it a mixed activity, of great value for the students for what it means of active learning and development of transversal competences such as teamwork or oral communication in public.

The accumulated experience with this activity has been very positive. So much so that it has been carried out continuously since the beginning of this subject in the 2012/2013 academic year with the implementation of the degrees. Among the innovations that have been introduced throughout these 7 editions, two of them are worth highlighting: on the one hand, the adaptation to bilingual teaching in Spanish and English, and on the other hand the opening of the workshop sessions to the entire School staff (ETSIT), both students and teachers. For this purpose, this activity is publicized in the corresponding dissemination lists of the School and is carried out in an environment suitable for public assistance such as the conference room. As an example of the benefits obtained with this opening, it is worth mentioning that during one of the sessions a fruitful discussion was established between the student speakers and a professor who attended the session, which subsequently led to the completion of a final degree project, a Master thesis, and three publications in indexed journals.

The teaching load assigned to this activity is 1.5 hours of face-to-face activity plus 9 hours of nonface-to-face work for the preparation of the expositions, out of a total of 6 ECTS (or 180 hours) of overall subject load. The teaching guide contains very detailed information on competencies and learning outcomes, content, aims, teaching and evaluation methodology, bibliography and digital media.

\subsection{Project-Based Learning}

The second of the specific applications that we are going to present is carried out in the optional subject of the fourth course "Design and Manufacture of Electronic Circuits". This subject is a clear example of project-based learning. As it is an optional subject, the number of students enrolled favors the application 
of this methodology. The fact that the theoretical and practical teaching hours of this subject are concentrated in a single continuous session of 4 hours per week also contributes to this. This allows working in the laboratory during those 4 hours, interspersing the explanations of the teacher on the blackboard available in the laboratory with the work of the students in their practice places. To this end, a laboratory was specially designed for this purpose with U-shaped benches arranged around a blackboard, in such a way as to enable the vision of it and the teacher from any work place. Thus the teacher can easily address all students and can supervise their work without having to move continuously from one end of the laboratory to the other. From the first to the last day of class, students work in the laboratory following the flow of tasks described in Figure 2 for project-based work. The aim is the development of an electronic prototype going through all its phases, from its conception and determination of its performance, to the design, manufacture, and finally verification and testing. In this way many skills are worked, which condense to a large extent all the knowledge of Electronics acquired in the previous subjects of the degree. As an example, in the 2018/2019 academic year the proposed project consists of a transmission system with FM modulation. The system consists of several modules, each of which is assigned to a group of students, which is responsible for its design fulfilling the specifications established for the system to work properly when the various stages are connected. This way of working is very instructive for the students, since it constitutes a training in the work methods that they will find in the exercise of their profession and a preparation for the assumption of responsibilities, while providing great satisfaction, since at finalizing the project they have a complete vision of the development of an electronic product and a feeling of understanding the usefulness of everything they have previously studied in the Electronic subjects of the degree.

This example of project-based learning is really innovative for several reasons. First, if we compare it with traditional practical teaching in electronics, we see that this has been done so far on test circuit assembly plates called "protoboards" or circuit assembly plates by insertion. In this type of plates the electronic components (resistors, capacitors, transistors, integrated circuits, etc. ...) are inserted into the holes of the assembly plates and connected by flexible external cables, so that no welding is necessary and all material is recovered after practice to be reused. However, this is not the way to work in industry applications, where circuits are made on printed circuit boards with photolithography techniques to define interconnection tracks and using various types of welding techniques to connect and fix components. It is difficult to introduce this type of techniques in university practical teaching, due to the expense of fungible material and the convenience of having a support staff with the necessary training. For this reason, our experience is a pioneer in this field and can serve as an example for other subjects. Another novelty of our approach is the collaborative work that involves the fact that each group of students must develop a part of the global project, so that by bringing the different parts together the system will work. It is a novel approach compared to the traditional practice in which each group worked in a self-sufficient way performing and testing their assembly. Our new way of working brings numerous advantages, including the development of competences for teamwork and for the development of a sense of responsibility at work, allowing students to realize that the success of a company can depend on the correct performance of our part of the work, no matter how big or small our contribution may seem.

The complete subject of "Design and Manufacture of Electronic Circuits" is based on the methodology of project-based learning, so we can say that all its teaching load (6 ECTS) is impregnated with this methodology. At the end of the course a presentation of the global project is made, in which each group presents its part. This face-to-face activity is 1.2 hours, plus 23.6 hours of non-face-to-face work deemed necessary for the preparation of the presentation. The evaluation is carried out based on this presentation and the work done during the subject (presentation of reports and laboratory work), so the final exam has disappeared from this subject.

\subsection{Innovations in the Theoretical Lectures: Dialogued Class and Historicist Method}

In the second course subjects "Electronic Components and Devices" and "Electronic Circuits and Functions", it is more complicated to introduce the previous methodologies due to the high number of students enrolled. Therefore, it is necessary to look for other active learning methods that recognize and 
take into account the fact that not all students learn in the same way and that the attention and understanding of students during the traditional theoretical lecture cannot be taken for granted. To this end we have developed our own methodology, which we have called historicist in reference to the philosophical current born in the nineteenth century and which argues that the nature of human works is only understandable if they are considered as an integral part of a continuous historical process. Based on this concept, we build the lecture from historical subsections in which we comment on the history of microelectronics, such as anecdotes that surrounded the invention of the transistor or brief biographical reviews of its protagonists. We also comment on aspects of economic or social nature such as the repercussions of the development of the microelectronic industry. These subsections contribute to stimulate the curiosity of the students and help a lot to maintain their attention. Another tool that we use for this purpose is what we call "dialogued class", and which consists in developing the theoretical lecture in a constant dialogue of questions and answers with the students, encouraging them to constantly think about the next step that we are going to take in the theoretical exposition. It can therefore be affirmed that it is the students themselves who are building the theoretical development of the lecture, guided by the teacher.

On the other hand, it should be noted that both subjects have a great practical load, specifically the same number of practical credits as theoretical (3 ECTS of each type). Practical activities include both laboratory work and problem classrooms. Laboratory practices have been designed to some extent with elements inspired by project-based learning, since the scripts that students must follow are not a mere recipe for instructions that can be followed mechanically, but often pose a challenge and invite to the student to freely look for his solution. On the other hand, problem classrooms sometimes incorporate the methodology of the flipped classroom, in which students are invited to bring a problem prepared in advance and solve it in front of their classmates and the teacher. It is worth mentioning that the practical lectures, both laboratory and problem solving, take place in groups much smaller in size than the theoretical lectures, which facilitates the application of these active learning methodologies.

\subsection{Complementary Activities}

Occasionally we have also used complementary activities to reinforce the subjects of Electronics. These include a trip to the National Microelectronics Center of Barcelona, where the largest clean micro/nano-manufacturing room in Spain is located. During this visit, students were able to see the equipment commonly used in microelectronic manufacturing, such as photolithography systems, ion implantation, thin film growth, plasma etching, and a long list of complementary techniques and supporting infrastructures. This visit provides students with a vision of the complexity of the manufacturing processes of the microelectronic industry, which have made it possible to achieve absolutely amazing levels of integration in the microchips manufactured today by the large companies in the sector. It also allows us to get an idea of the equipment cost, which has reached such exorbitant levels that only a few companies worldwide can face. To get an idea, the investment in R\&D of the top 10 companies in the sector reached an impressive amount of 36,000 million dollars in 2017, which represents a percentage of investment in research with respect to income of these companies much higher than any other industry (for example, $21 \%$ in the case of Intel). Courses have also been organized with foreign visiting professors of international relevance in topics ranging from photonic crystals to microelectronic manufacturing technology. These courses allow students to make contact with foreign leaders in research fields related to electronics, or with industry experts who can give an updated and first-hand view of what is being forged in the microelectronics industry production centers. Since these production centers are located abroad (especially around technological poles such as Silicon Valley, Israel, or Taiwan, to name a few), it is an activity that is part of the internationalization of the university. It also contributes to teaching innovation from the point of view of bilingual teaching, since these sessions usually take place in English. These courses have been recognized as credits of free configuration, and in some cases also as a specific training course, with a typical duration between 20 and 30 teaching hours (3 ECTS). 


\section{Evidences and Impact Evaluations of the Proposed Methodology}

The process of implementing the degrees adapted to the framework of the European Higher Education Area (EHEA) began in the 2010/2011 academic year and culminated in the 2014/2015 academic year. Since that time, the proposed method in the subjects of Electronics has been applied to students of a degree in Telecommunications Systems Engineering and Telematics Engineering of the Polytechnic University of Cartagena.

The impact of the proposed methodology has been analyzed through a comparative study of the results of the surveys carried out to the students by the quality service of the university. Figure 4 graphically shows the improvements achieved through the application of this methodology in the teaching of the Electronics area. The answers of the students in the satisfaction surveys with the teaching activity of the teaching staff have been represented in a graph. For this, the last of the questions asked in these surveys has been chosen, which refers to the degree of general satisfaction. The literal text of the question is the following: "In general terms I am satisfied with the teaching activity developed by the teacher". It is therefore a Likert element (Norman, 2010), in which the student evaluates their degree of agreement on a 5-point scale from 1 to 5 . In the graph of Figure 4 we have represented the average of the answers to this question for all the subjects of the Electronics area that have implemented the methodology developed in this article, as well as the average of all the subjects of the Polytechnic University of Cartagena. The results are offered as a function of time, for academic courses from 2014/2015 to the last course for which data are available at the time of preparing this study, that is, the 2017/2018 course. The reason for choosing this time interval is that the 2014/2015 course was the first in which the degrees adapted to the European Higher Education Area were fully implemented, and therefore the results are not affected by the coexistence of subjects in the old and new frameworks. We can see that the results for the university average are approximately constant, with small fluctuations. On the contrary, the results for the average of the subjects of the Electronics area initially start from a disadvantageous position compared to the average of the university (position that we attribute to the intrinsic difficulty of the Electronic subjects), but they experience a remarkable improvement during the period of implementation of this methodology and finally reach, and even exceed in one case, to the mark of the university at the end of the period.

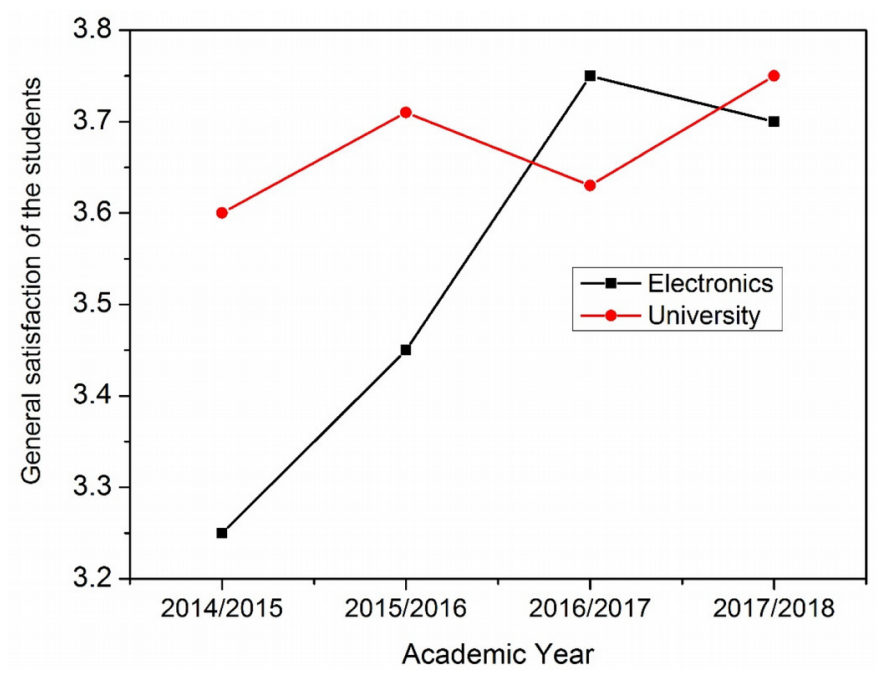

Figure 4. Results of student satisfaction surveys for the average of the subjects in the Electronics area and the average for the university

Surveys were also passed to full-time teaching staff who teach the subjects of Electronics in the degrees of the Higher Technical School of Telecommunications Engineering (ETSIT) of the Polytechnic University of Cartagena (UPCT). The following two considerations were used to assess the impact of this method: 
- Interest of teachers in applying this teaching-learning method in Electronic subjects.

- Capacities and knowledge achieved by students by means of this teaching-learning method.

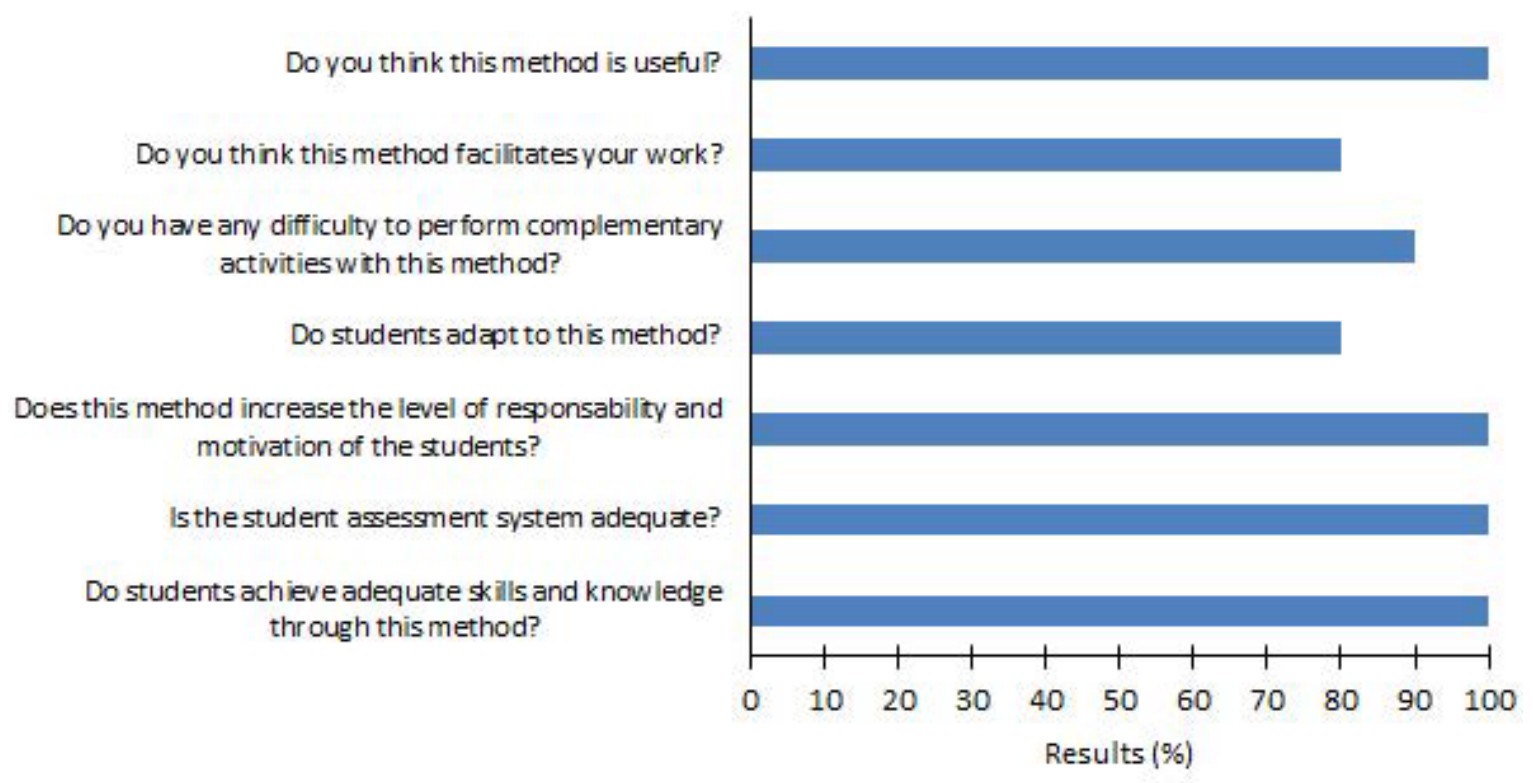

Figure 5. Results for the teacher surveys

For both considerations, anonymous surveys were passed to 10 teachers who have been using this teaching-learning method since the 2014/2015 academic year to 2017/2018. Part-time teacher surveys could not be carried out, since they do not have a presence in the Electronics area of the Department that teaches the subjects of Electronics in the degrees of the ETSIT of the UPCT.

In the case of the first consideration (Figure 5), the surveys revealed that:

- $100 \%$ of teachers believe that the method is useful, since its scientific approach is well suited to the teaching-learning of Electronic subjects.

- $80 \%$ consider that they have improved their work by applying this method, due to the homogenization of the teaching methodology in the Electronic subjects.

- $90 \%$ indicate that it is difficult to perform any complementary activity. According to the comments of the professors, and although these activities are optional, there are too many subjects during the semester that make it impossible to find free time slots to schedule any of the complementary activities. In addition, they receive complaints from students (undergraduate) about the time and work burden that this entails.

For the second consideration (Figure 5), the surveys showed that:

- $80 \%$ of teachers estimate that students adapt adequately to the method when applying the different activities. The most difficult activity of teachers is to maintain active attitudes of students during the theoretical lectures.

- $100 \%$ consider that the level of responsibility and motivation of the students in the different activities of an Electronic subject increases throughout the course, due to a greater participation of the students in these.

- $100 \%$ think that the system used for the evaluation of students is adequate, since it has an objective characteristic.

- $100 \%$ indicate that students achieve adequate skills and knowledge by means of this teaching-learning method. 
Since the 2014/2015 academic year in which the proposed method has been applied, and as a result, the methodology for teaching the subjects of Electronics and the coordination between professors of the department has been improved and homogenized. This improvement is reflected in Figure 4, where it can be seen that the satisfaction of the students with the Electronic subjects has been growing since the beginning (2014/2015 academic year) to stabilize today. The teaching of Electronics at the university level usually presents a special difficulty for students, mainly in the first subjects found in this matter. Unlike other subjects of fundamental type such as physics or mathematics (which are gradually introduced in high school), the common situation in relation to electronics is that students have not seen anything related to it or its basic concepts before, and meet it for the first time in university. This has as a consequence an initial situation of perplexity that can result in misunderstanding or even rejection of the students towards the Electronic subjects, as was the case at the beginning of the implementation of the proposed method (Figure 4). To reverse this situation, the teachers were involved in developing the content of the subjects in accordance with the curricula of the degrees in Telecommunications Systems Engineering and Telematics Engineering of the Polytechnic University of Cartagena, since it is important to place the Electronics subjects in relation to the profession (Telecommunications Engineer). The teachers noticed positive changes in student behavior during the classes, in terms of achieving greater participation and motivation of the students in the different activities. Given the scientific-technical nature of Electronics, they also highlighted a great progress of students in the development of related experimental skills such as: handle electronic instruments and components; experimentally check theoretical explanations; analyze data and draw conclusions; learn to combine design with analysis and write technical reports.

To improve the teaching methodology of Electronics, studies prior to ours have been carried out, both national (Herrero, Pardo, Fernando \& González, 2011) and international (Patil \& Prasad, 2016). In comparison with these studies, which refer to the particular context of industrial engineering (Herrero et al., 2011) or of a specific country (Patil \& Prasad, 2016), our work focuses on Electronics understood as a fundamental subject for Information Technology and Communications. It also has the advantage that it has been applied once the process of implementation of the European Higher Education Area (EHEA) has been completed, so that its effectiveness can be evaluated (Figure 4) without being affected by coexistence with study frameworks prior to the EHEA. Therefore, the cause of the positive evolution of the results reflected in Figure 4 is solely attributable to the application of this methodology.

\section{Conclusion}

This article has described the teaching-learning model used in four Electronics subjects, taught in Telecommunications engineering studies at the Polytechnic University of Cartagena (UPCT). One of the three subjects is of a basic or fundamental type, while the other two are mandatory and one is optional. In this model we can highlight the emphasis on the part of the teachers to achieve the didactic aims of the different subjects of Electronics through active learning activities, avoiding passive attitudes of the students, promoting responsibility and ethics, boosting learning and promoting competence development The motivation and learning of the students in the Electronic subjects are reinforced through the practical activities. The impact of the methodology has been visualized through the results of the student satisfaction surveys with the teaching activity of the teachers, which show a clear positive trend for the subjects of the Electronics area during the period in which this methodology has been implemented. Teacher surveys have shown an almost absolute predisposition to apply this method, since it focuses well on Electronics subjects, facilitates their work and students achieve adequate skills and knowledge. They have also positively appreciated the adaptation of the students to the method, because of the increase in their participation in the different activities of the Electronics subjects during the course.

\section{Declaration of Conflicting Interests}

The authors declared no potential conflicts of interest with respect to the research, authorship, and/or publication of this article. 


\section{Funding}

This work was carried out as part of the UPCT teaching innovation project with reference: EXP2019/005432.

\section{References}

Álvarez-Pérez, P.R. (2013). La función tutorial del profesorado universitario: una nueva competencia de la labor docente en el contexto del EEES. Revista Portuguesa de Pedagogía, 47(2), 85-106. https://doi.org/10.14195/1647-8614_47-2_5

Apperson, J.M., Laws, E.L., \& Scepansky, J.A. (2008). An assessment of student preferences for powerpoint presentation structure in undergraduate courses. Computer \& Education, 50(1), 148-153. https://doi.org/10.1016/j.compedu.2006.04.003

Bergmann, J., \& Sams, A. (2012). Flip your classroom: reach every student in every class every day. Washington, USA: International Society for technology in Education.

Bloom, B.S., Hastings, J.T., \& Madaus, G.F. (1975). Evaluación del aprendizaje. Buenos Aires, Argentina: Troquel.

Cobo-Ortega, A. (2015). Análisis sobre las implicaciones de la nueva estructura de las titulaciones oficiales: el esquema “3+2”. Revista Universidad, Ética y Derechos. https://doi.org/10.25267/Rueda.2015.10

Díaz-Álvarez, A, \& Pons-Fanals, E. (2011). La adaptación del sistema universitario español a las nuevas demandas sociales: desde los objetivos a las reformas. Revista d'Innovació Docent Universitària, 3, 86-98. https://doi.org/10.1344/105.000001660

Dutson, A.J., Todd, R.H., Magleby, S.P., \& Sorensen, C.D. (1997). A review of literature on teaching engineering design through project-oriented capstone courses. Journal of Engineering Education, 86(1), 17-28. https://doi.org/10.1002/j.2168-9830.1997.tb00260.x

Felder, R.M., \& Silverman. L.K. (1988). Learning and teaching styles in engineering education. Engineering Education, 78(7), 674-681.

García-Sanpedro, M.J. (2012). Feedback and feedforward: Focal points for improving academic performance. Journal of Technology and Science Education, 2(2), 77-85. https://doi.org/10.3926/jotse.49

Gezuraga-Amundarain, M., \& Malik-Liévano, B. (2015). Orientación y acción tutorial en la universidad desde el aprendizaje-servicio. Revista Española de Orientación y Psicopedagogía, 26(2), 8-25.

https://doi.org/10.5944/reop.vol.26.num.2.2015.15213

González, S., \& Triviño, M.A. (2018). Las estrategias didácticas en la práctica docente universitaria. Profesorado. Revista Currículum y Formación del Profesorado, 22(2), 371-388.

https://doi.org/10.30827/profesorado.v22i2.7728

Gotsick, J.E., \& Gotsick, P.S. (1996). Multimedia in the classroom. Behavior Research Methods, Instrument \& Computers, 28(2), 291-294. https://doi.org/10.3758/BF03204784

Haladyna, T., \& Shaughnessy, J. (1982). Attitudes toward science: a quantitative synthesis. Science Education, 66(4), 547-563. https://doi.org/10.1002/sce.3730660406

Herrero, L.C., Pardo, F., Fernando, M.L., \& González, M.L. (2011). Reflections and conclusions on the work developed by the group of teaching innovation in Electronics at the University of Valladolid. Journal of Technology and Science Education, 1(2), 3-15. https://doi.org/10.3926/jotse.2011.21

Klopfer, L.E. (1976). A structure for the affective domain in relation to science education. Science Education, 60(3), 299-312. https://doi.org/10.1002/sce.3730600304

Lodico, M.G., Spaulding, D.T., \& Voegtle, K.H. (2006). Methods in educational research from theory to practice. San Francisco, USA: Wiley. 
Norman, G. (2010). Likert scales, levels of measurement and the "laws" of statistics. Advances in Health Sciences Education, 15(5), 625-632. https://doi.org/10.1007/s10459-010-9222-y

Nunes de Oliveira, J.M. (2011). Nine years of Project-based learning in engineering. Revista de Docencia Universitaria, 9(1), 45-55. https://doi.org/10.4995/redu.2011.6179

Patil, S.A., \& Prasad, S.R (2016). Innovative methods of teaching and learning electronics engineering. Journal of Engineering Education Transformations, Special Issue. https://doi.org/10.16920/jeet/2016/v0i0/85656

Rodríguez-García, A.M., Hinojosa-Lucena, M.A., \& Ágreda-Montoro, M. (2017) Análisis del uso de vídeo-tutoriales como herramienta de inclusión educativa. Publicaciones, 47, 13-35.

Vidal-Prado, C. (2012). El espacio europeo de educación superior y su implantación en las universidades españolas. Revista Catalana de dret públic, 44, 253-283.

Villardón-Gallego, L. (2006). Evaluación del aprendizaje para promover el desarrollo de competencias. Educatio Siglo XXI, 23, 57-76.

Walvoord, B.E., \& Anderson, V.J (2010). Effective grading: a tool for learning and assessment in college. San Francisco, USA: Wiley.

Published by OmniaScience (www.omniascience.com)

Journal of Technology and Science Education, 2020 (www.jotse.org)

\section{(c) $\underset{\mathrm{BY}}{\mathrm{BY}(\mathrm{NC})}$}

Article's contents are provided on an Attribution-Non Commercial 4.0 Creative commons International License. Readers are allowed to copy, distribute and communicate article's contents, provided the author's and JOTSE journal's names are included. It must not be used for commercial purposes. To see the complete licence contents, please visit https://creativecommons.org/licenses/by-nc/4.0/. 